\title{
Retrospective study of the differential diagnosis between cryptogenic multifocal ulcerous stenosing enteritis and small bowel Crohn's disease
}

\author{
Dan Chen ${ }^{1}$, Wei Liu², Weixun Zhou ${ }^{3}$, Weiyang Zheng ${ }^{1}$, Dong Wu ${ }^{1 *+}$ and Jiaming Qian ${ }^{1 *+}$
}

\begin{abstract}
Background: Being a rare disease, cryptogenic multifocal ulcerous stenosing enteritis (CMUSE) is easily misdiagnosed as small bowel Crohn's disease (SBCD).

Aims: This study was aimed to compare clinical features of CMUSE to SBCD.

Methods: Fourteen patients with CMUSE and 61 patients with SBCD were retrospectively analyzed.

Results: Hematochezia was more frequent in CMUSE patients $(10,71.4 \%$ vs $23,37.7 \%, P=0.022)$, while diarrhea was more common in SBCD patients $(23,37.7 \%$ vs $0,0.0 \%, P=0.015)$. More patients with CMUSE developed intestinal stenosis than with $\operatorname{SBCD}(14,100 \%$ vs $37,60.7 \%, P=0.011) .30$ (50.0\%) SBCD patients and none CMUSE patients had an elevated erythrocyte sedimentation rate level $(P=0.001)$. Extra-enteric findings found by computed tomography enterography were significantly more prevalent in SBCD patients than in CMUSE patients $(25,71.4 \%$ vs 3,25\%, $P=0.013)$. Longitudinal ulcers found by endoscopy were more common in SBCD patients $(16,37.2 \%$ vs $0,0.0 \%$, $P=0.041)$, while circumferential ulcers were more common in CMUSE patients $(6,54.6 \%$ vs $8,18.6 \%, P=0.041)$. All ulcers observed in CMUSE patients were within mucosal and submucosal layers, but 8 (44.4\%) SBCD patients had deep ulcers that reached beyond submucosal layers $(P=0.003)$. Ulcers were located at strictures in $9(90.0 \%)$ CMUSE patients but only in $1(5.6 \%)$ SBCD patient $(P=0.000)$.
\end{abstract}

Conclusions: Gastrointestinal symptoms, erythrocyte sedimentation rate levels, radiologic, endoscopic and pathologic features help to distinguish CMUSE from SBCD.

Keywords: Cryptogenic multifocal ulcerous stenosing enteritis, Small bowel Crohn's disease, Small intestinal ulcer, Differential diagnosis

\footnotetext{
*Correspondence: qianjiaming1957@126.com; wudong@pumch.cn

+ Jiaming Qian and Dong Wu contributed equally to this work.

'Department of Gastroenterology, Peking Union Medical College Hospital,

Chinese Academy of Medical Sciences and Peking Union Medical College,

Shuaifuyuan, No.1, Dongcheng District, Beijing 100730, China

Full list of author information is available at the end of the article
}

(c) The Author(s). 2020 Open Access This article is licensed under a Creative Commons Attribution 4.0 International License, which permits use, sharing, adaptation, distribution and reproduction in any medium or format, as long as you give appropriate credit to the original author(s) and the source, provide a link to the Creative Commons licence, and indicate if changes were made. The images or other third party material in this article are included in the article's Creative Commons licence, unless indicated otherwise in a credit line to the material. If material is not included in the article's Creative Commons licence and your intended use is not permitted by statutory regulation or exceeds the permitted use, you will need to obtain permission directly from the copyright holder. To view a copy of this licence, visit http://creativecommons.org/licenses/by/4.0/ The Creative Commons Public Domain Dedication waiver (http://creativecommons.org/publicdomain/zero/1.0/) applies to the data made available in this article, unless otherwise stated in a credit line to the data. 


\section{Background}

Cryptogenic multifocal ulcerous stenosing enteritis (CMUSE) is a rare condition affecting the small bowel, characterized by multiple unexplained ulcerations and strictures without systemic inflammation typically, but not always, in middle-aged or young patients. The etiology is unknown and pathogenesis is poorly understood. Abdominal pain, ileus and hematochezia are its common symptoms. Extra-intestinal manifestations of CMUSE include oral aphthae, joint pain, Raynaud's phenomenon, sun allergy and neuropathy [1].

Crohn's disease (CD) is an intestinal inflammatory disease but can affect the entire gastrointestinal tract. Small bowel is involved in almost $80 \%$ of the cases [2]. Small bowel Crohn's disease (SBCD) is defined as CD with lesions mainly located in the small bowel which occur in as many as one third of CD patients [3]. Typical presentations include the presence of longitudinal ulcers with a cobblestone appearance, skip lesions, and the development of complications such as strictures and fistulas. Oral ulcers, arthralgia, erythema nodosum, and autoimmune hepatic diseases are its extra-intestinal manifestations.

Less than 100 cases of CMUSE have been published worldwide since it was first described by Debray et al. in 1964 [4]. A retrospective study in Korea reported that 90\% CMUSE patients had been misdiagnosed with SBCD [5]. Both CMUSE and SBCD are chronic recurrent diseases, with similar gastrointestinal symptoms and multiple ulcerations and strictures of the small intestine. Distinguishing between them is challenging but important, since the treatment and prognosis of CMUSE differs from $\operatorname{SBCD}[3,6]$. To our knowledge, there are just 3 case reports [7-9] and 2 case series [1, 10] of CMUSE proposing some points for differentiation. No comparative study regarding the differential diagnosis between CMUSE and SBCD has been done so far. Therefore we conducted this retrospective study to investigate clinical features of CMUSE and SBCD to find out the main points beneficial for differentiation between them.

\section{Methods}

\section{Patients}

This was a retrospective study in a single center. The medical records of 14 patients with CMUSE from August 1984 to March 2017 in Peking Union Medical College Hospital, Beijing, China were reviewed. The control group of 61 patients with small bowel Crohn's disease (SBCD) was selected from our IBD database using the simple random method with the procedure of "SURVEYSELECT" of SAS package. All patients were followed up for at least 12 months. Patients diagnosed with Crohn's disease with colorectal lesions, ulcerative colitis, intestinal tuberculosis, Behcet's disease, neoplasms, or other recognized causes of intestinal inflammation were excluded.
Diagnostic criteria of small bowel Crohn's disease

A diagnosis of SBCD was established by clinical evaluation and a combination of endoscopic, histological, radiological, and/or biochemical investigations according to 3rd European Evidence-based Consensus on the Diagnosis and Management of Crohn's Disease 2016 [11].

\section{Diagnostic criteria of cryptogenic multifocal ulcerous stenosing enteritis}

The diagnostic criteria for CMUSE were [5]: (1) unexplained small bowel strictures or ileus; (2) superficial ulcer in the mucosa and submucosa; (3) chronic or relapsing ulcerative stenosis of the small bowel after surgical resection; (4) no signs of systemic inflammation; (5) improvement after administering corticosteroids; (6) excluding other small intestine ulcerative disease. We recommended that a complete CMUSE be diagnosed if pathologic findings show that superficial ulcer is limited within mucosal and submucosal layers, and a suspected CMUSE be diagnosed if lacking of surgical resection and pathologic examination could not been done. In this study, $10(71.4 \%)$ and $4(28.6 \%)$ patients were diagnosed as complete and suspected CMUSE, respectively. In fact, seven CMUSE patients had been misdiagnosed with $C D$, and one with intestinal tuberculosis, Meckel diverticulum and ischemic bowel disease, respectively.

\section{Clinical, laboratory, radiologic, endoscopic, and pathologic features}

Demographics (gender, age at gastrointestinal symptom onset and disease duration), the history of appendectomy, medication history of nonsteroidal anti-inflammatory drugs (NSAIDs) for more than 2 weeks, body mass index (BMI), clinical manifestations (symptoms, extra-intestinal manifestations, gastrointestinal complications, and lesion distribution), laboratory findings, radiologic features, endoscopic abnormalities, and pathologic features were collected. Haematochezia is defined as overt bloody stool. Lesion distribution was determined by radiologic and endoscopic examinations and surgical operation. Terminal ileum was defined as ileum that was within $30-\mathrm{cm}$ of ileocecal valve. Radiologic features included skip lesions, enteric findings (ulcers, bowel strictures, bowel wall thickening, mural hyperenhancement, rough serosa, pseudodiverticulum and pseudo-polyps) and extraenteric findings (comb sign, enhanced density of the peri-intestinal fat, enlargement of the abdominal lymph nodes, and fistula) on CTE. Endoscopic features included the presence and number of ulcers ( 1 , or $\geq 2$ ), ulcer types (longitudinal ulcer, dot ulcer, circumferential ulcer, oval ulcer, aphthous ulcer or irregular ulcer), number of strictures (1, or $\geq 2)$, fistula, hyperplastic lesions (pseudo-polyps, nodular lesions or eminence lesions) and cobblestone appearance detected by double-balloon enteroscopy, coloscopy or 
capsule endoscopy. Aphthous ulcer was defined as a tiny, punched out, raised or flat red lesion with a white center.

Operation data included the number of patients underwent operation and the surgical indications. All samples for histopathological examination were surgical samples. Pathological feature included ulcer incidence, ulcernumber $(1$, or $\geq 2)$, the depth of the deepest ulcer (deep, or superficial, superficial ulcer means ulcer limited within mucosal and submucosal layers), ulcer located on stricture site, stricture number (1, or $\geq 2)$, cobblestone appearance, perforation, fistula, transmural inflammation, non- caseous epithelioid granulomas, and abscess. Images of radiologic, endoscopic or pathologic examinations were respectively reviewed by a radiologist (Wei Liu), an endoscopic expert (Weiyang Zheng) or pathologist (Weixun Zhou) who was blinded to the design of this study.

\section{Statistical analysis}

SPSS 22.0 was used for data analysis. Continuous variables were presented as mean \pm standard deviation (SD) or medians with interquartile range. Differences in quantitative data between the two groups were analyzed by independent t-test for continuous variables followed normal distribution or by non-parametric test for continuous variables not coincided with normal distribution. Chi-squared test or Fisher's exact test were used for categorical variables. $P$ values were two-tailed, and $P$ value of $<0.05$ was considered to be statistically significant.

\section{Results}

\section{Demographics and clinical features}

Table 1 shows demographics and some clinical data of CMUSE patients and SBCD patients. No significant difference was found with respect to the patients' gender, age, disease duration, the history of appendectomy and BMI. No patients reported to have used NSAIDs for more than 2 weeks.

Abdominal pain was not only the most common reporting symptom $(8,57.1 \%$ vs $36,59.0 \%, P=0.898)$ but also the most frequent gastrointestinal symptom (12, $85.7 \%$ vs $56,91.8 \%, P=0.844$ ) in both CMUSE patients and SBCD patients. Hematochezia was more frequent in CMUSE patients $(10,71.4 \%$ vs $23,37.7 \% ; P=0.022)$, while diarrhea was more common in CD patients (23, $37.7 \%$ vs $0,0.0 \%, P=0.015$, respectively). CMUSE patients $(14,100.0 \%)$ had a significantly higher incidence of developing intestinal stenosis than $\operatorname{SBCD}(37,60.7 \%)$ $(P=0.011)$. Terminal ileum was found to be more frequently involved in SBCD patients $(38,62.3 \%)$ than CMUSE patients $(4,28.6 \%)(P=0.022)$. Upper gastrointestinal tract involved in one CMUSE patient manifested as duodenal ulcer. There was no significant difference in general symptoms or extra-intestinal manifestations

\section{Laboratory findings}

The laboratory findings of CMUSE patients and SBCD patients are listed in Supplementary Data Content 1. CMUSE patients $(12,92.3 \%)$ were more likely to develop anemia than SBCD patients $(36,60.0 \%)(P=0.028)$. The mean hemoglobin level of patients with CMUSE and SBCD were $93.2 \pm 27.6$ and $104.6 \pm 27.0 \mathrm{~g} / \mathrm{L}(P=0.164)$, respectively. Besides, $30(50.0 \%)$ of the patients with SBCD were observed to have elevated ESR levels, while none of the CMUSE patients had elevated ESR levels $(P=0.001)$. The levels of high sensitivity $C$ reactive protein (hsCRP) were elevated in more SBCD patients (39, $68.4 \%)$ than CMUSE patients $(4,28.6 \%),(P=0.006)$.

\section{Radiologic features}

The radiologic features (Fig. 1) found by CTE of CMUSE patients and SBCD patients are summarized in Table 2. Both groups were manifested as skip lesions on CTE. Extra-enteric findings were significantly more prevalent in SBCD patients $(25,71.4 \%)$ than in CMUSE patients (3, 25.0\%) $(P=0.013)$. Specifically, enlargement of the abdominal lymph nodes was more frequently observed in SBCD patients $(21,60.0 \%)$ than CMUSE patients (2, 16.7\%) $(P=0.010)$.

\section{Endoscopic features}

The endoscopic features (Fig. 2) of CMUSE patients and SBCD patients are listed in Table 3. Longitudinal ulcers were more common in SBCD patients $(16,37.2 \%$ vs 0 , $0.0 \%, P=0.041)$, while circumferential ulcers were more common in CMUSE patients $(6,54.6 \%$ vs $8,18.6 \%, P=$ 0.041). More patients with CMUSE developed strictures than with $\operatorname{SBCD}(9,69.2 \%$ vs $16,29.6 \%, P=0.020)$ and CMUSE patients were more likely to have multiple strictures compared to SBCD patients $(4,44 \%$ vs $3,18.7 \%, P=$ 0.013). Cobblestone appearance, which was considered as the characteristic change of $\mathrm{CD}$, tended to be observed in more SBCD patients $(4,7.4 \%)$ than CMUSE patients $(0$, $0.0 \%)$, but the differences were not significant $(P=1.000)$.

\section{Surgical operations}

Operation data of CMUSE and SBCD patients including proportion of patients underwent surgery and surgical indications are summarized in Supplementary Data Content 2. 10 (71.4\%) CMUSE patients and 25 (41.0\%) SBCD patients underwent at least one intestinal operation $(P=$ 0.039 ). Ileus was the most common surgical indication for both CMUSE patients $(6,60.0 \%)$ and SBCD patients $(12,48.0 \%)(P=0.711)$. 
Table 1 Demographic and clinical features of CMUSE and SBCD patients

\begin{tabular}{|c|c|c|c|c|c|}
\hline \multirow[t]{2}{*}{ Characteristics } & \multicolumn{2}{|c|}{ CMUSE } & \multicolumn{2}{|c|}{ SBCD } & \multirow{2}{*}{$\begin{array}{l}P \\
\text { valu }\end{array}$} \\
\hline & $\mathrm{N}$ & n (\%) or median/mean & $\mathrm{N}$ & n (\%) or median/mean & \\
\hline \multicolumn{6}{|l|}{ Demographics } \\
\hline Gender (male, n (\%)) & 14 & $8(57.1)$ & 61 & $34(55.7)$ & 0.924 \\
\hline Disease duration (months, median $\left(\mathrm{P}_{25}, \mathrm{P}_{75}\right)$ ) & 14 & $33.5(11.3-168.0)$ & 61 & $24.0(5.5-84.0)$ & 0.320 \\
\hline The history of appendectomy (n (\%)) & 14 & $5(35.7)$ & 61 & $13(21.3)$ & 0.429 \\
\hline Medication history of NSAIDs for more than two weeks $(n(\%))$ & 14 & $0(0.0)$ & 61 & $0(0.0)$ & 1.000 \\
\hline $\mathrm{BMI}($ mean $\pm \mathrm{SD})$ & 7 & $18.68 \pm 1.65$ & 49 & $19.25 \pm 3.32$ & 0.659 \\
\hline \multicolumn{6}{|l|}{ General symptoms (n (\%)) } \\
\hline Fever & 14 & $3(21.4)$ & 61 & $29(47.5)$ & 0.075 \\
\hline Weakness & 14 & $8(57.1)$ & 61 & $27(44.3)$ & 0.384 \\
\hline Weight loss & 14 & $8(64.3)$ & 61 & $48(78.7)$ & 0.429 \\
\hline \multicolumn{6}{|l|}{ Gastrointestinal symptoms (n (\%)) } \\
\hline Poor appetite & 14 & $6(42.9)$ & 61 & $37(60.7)$ & 0.225 \\
\hline Hematochezia & 14 & $10(71.4)$ & 61 & $23(37.7)$ & 0.022 \\
\hline Abdominal pain & 14 & $11(85.7)$ & 61 & $56(91.8)$ & 0.844 \\
\hline Intestinal distention & 14 & $8(57.1)$ & 61 & $25(41.0)$ & 0.272 \\
\hline Vomiting & 14 & $8(57.1)$ & 61 & $27(44.3)$ & 0.384 \\
\hline Diarrhea & 14 & $0(0.0)$ & 61 & $23(37.7)$ & 0.015 \\
\hline Abdominal mass & 14 & $4(28.6)$ & 61 & $21(34.4)$ & 0.917 \\
\hline Perianal lesions & 14 & $1(7.1)$ & 61 & $3(4.9)$ & 0.571 \\
\hline Extra-intestinal manifestations ( $\mathrm{n}(\%)$ ) & 14 & $3(23.1)$ & 61 & $28(45.9)$ & 0.130 \\
\hline Oral ulcers & 14 & $2(14.3)$ & 61 & $21(34.4)$ & 0.249 \\
\hline Genital ulcers & 14 & $0(0.0)$ & 61 & $3(4.9)$ & 1.000 \\
\hline Joint pain & 14 & $0(0.0)$ & 61 & $11(18.0)$ & 0.139 \\
\hline Skin lesions & 14 & $1(7.1)$ & 61 & $5(8.2)$ & 1.000 \\
\hline \multicolumn{6}{|l|}{ Gastrointestinal complications (n (\%)) } \\
\hline Perforation & 14 & $0(0.0)$ & 61 & $2(3.3)$ & 1.000 \\
\hline Fistula & 14 & $0(0.0)$ & 61 & $5(8.2)$ & 0.607 \\
\hline Intestinal stenosis & 14 & $14(100.0)$ & 61 & $37(60.7)$ & 0.011 \\
\hline Abscess & 14 & $0(0.0)$ & 61 & $3(4.9)$ & 1.000 \\
\hline \multicolumn{6}{|l|}{ Disease distribution (n (\%)) } \\
\hline Jejunum & 14 & $4(28.6)$ & 61 & $27(44.3)$ & 0.282 \\
\hline lleum & 14 & $13(92.9)$ & 61 & $57(93.4)$ & 1.000 \\
\hline Upper gastrointestinal tract & 14 & $1(7.1)$ & 61 & $6(9.8)$ & 1.000 \\
\hline Terminal ileum & 14 & $4(28.6)$ & 61 & $38(62.3)$ & 0.022 \\
\hline Ileocecal valve & 14 & $2(14.3)$ & 61 & 12 (19.7) & 0.931 \\
\hline
\end{tabular}

\section{Pathologic features}

Superficial ulcers and strictures were found in surgery pathology in all patients with CMUSE. Ulcers and strictures in $8(80 \%)$ patients with CMUSE were multiple. Cobblestone appearance, transmural inflammation and non- caseous epithelioid granulomas were absent in all the CMUSE cases. Table 4 shows the pathologic features (Fig. 3) of CMUSE patients and SBCD patients. There were significant differences in the ulcer location $(P=$ $0.000)$ and ulcer depth $(P=0.003)$ between the two groups. Ulcer was observed to be located on strictures in 9 (90.0\%) CMUSE patients but only in 1 (5.6\%) SBCD patient. All ulcers observed in CMUSE patients (10, $100 \%$ ) were superficial which were limited within mucosal and submucosal layers. Eight (44.4\%) SBCD patients had deep ulcers that reached out of submucosal layers. 

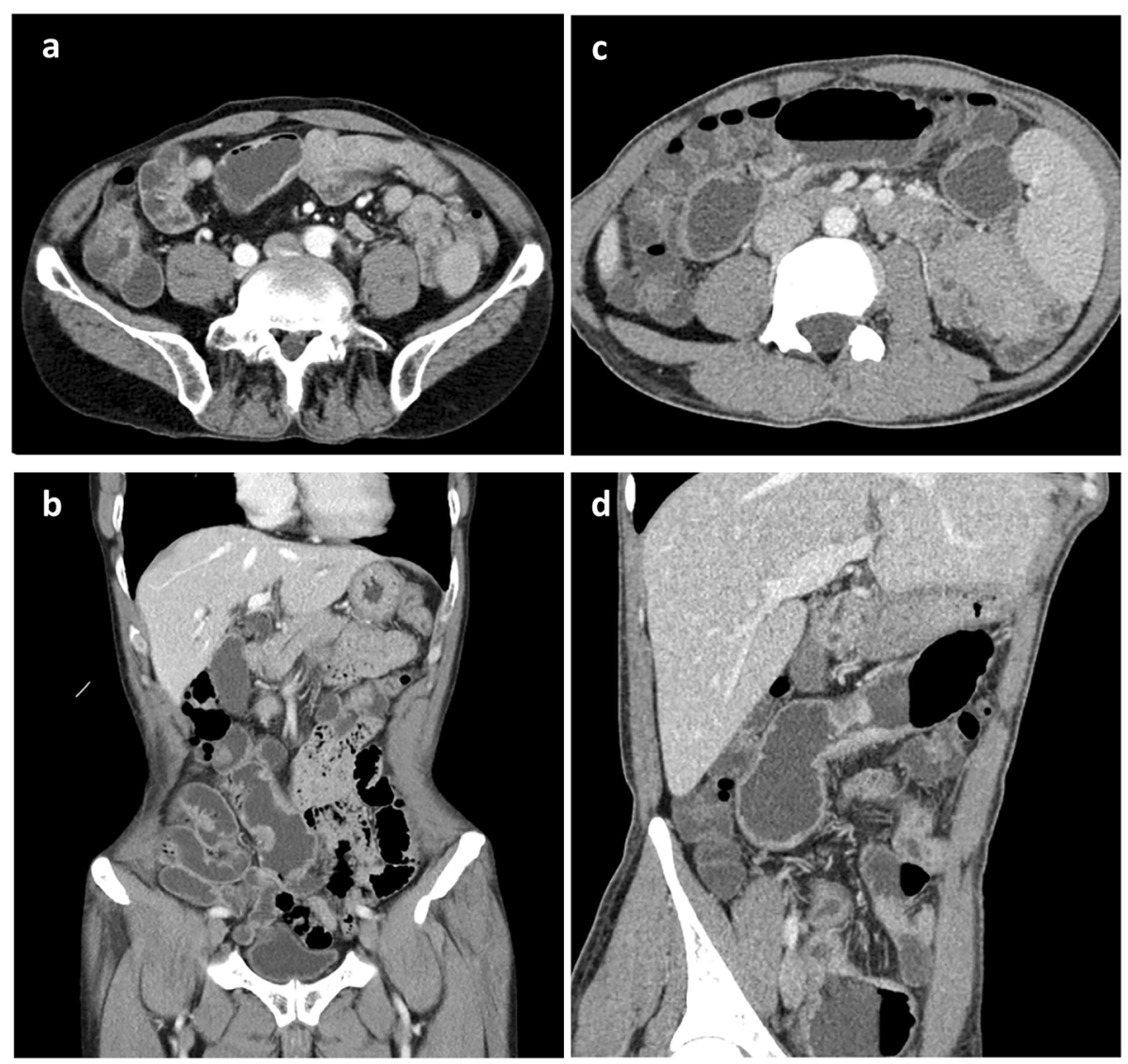

Fig. 1 The radiologic features of CMUSE and SBCD patients. a and $\mathbf{b}$ were CTE images from a patient with CMUSE showing multiple mild stenosis, luminal dilatationand and mild mucosal hyperenchancement of the ileum on the right side. $\mathbf{c}$ and $\mathbf{d}$ were CTE images from two patients with SBCD which showed multiple stenosis, mucosal hyperenchancement, thickened wall, roughness of serosa, luminal narrowing of the small intestine, and the comb sign

Table 2 Radiologic features of CMUSE and SBCD patients

\begin{tabular}{|c|c|c|c|c|c|}
\hline \multirow[t]{2}{*}{ Characteristics } & \multicolumn{2}{|c|}{ CMUSE } & \multicolumn{2}{|c|}{ SBCD } & \multirow[t]{2}{*}{$P$ valua } \\
\hline & $\mathrm{N}$ & $n(\%)$ & $\mathrm{N}$ & $n(\%)$ & \\
\hline Number of patients underwent CTE & 14 & $12(85.7)$ & 61 & $35(57.4)$ & I \\
\hline Skip lesions & 12 & $8(66.7)$ & 35 & $20(57.1)$ & 0.811 \\
\hline Enteric findings & 12 & $10(83.3)$ & 35 & $32(91.4)$ & 0.808 \\
\hline Ulcers & 12 & $0(0.0)$ & 35 & $2(5.7)$ & 1.000 \\
\hline Bowel strictures & 12 & $8(66.7)$ & 35 & $13(37.1)$ & 0.076 \\
\hline Bowel wall thickening & 12 & $10(83.3)$ & 35 & $30(85.7)$ & 1.000 \\
\hline Mural hyperenhancement & 12 & $7(58.3)$ & 35 & $29(82.9)$ & 0.181 \\
\hline Roughness of serosa & 12 & $0(0.0)$ & 35 & $8(22.9)$ & 0.170 \\
\hline Pseudodiverticulum & 12 & $1(8.3)$ & 35 & $5(14.3)$ & 1.000 \\
\hline Pseudo-polyps & 12 & $0(0.0)$ & 35 & $2(5.7)$ & 1.000 \\
\hline Extra-enteric findings & 12 & $3(25.0)$ & 35 & $25(71.4)$ & 0.013 \\
\hline Comb sign & 12 & $1(8.3)$ & 35 & $3(8.6)$ & 1.000 \\
\hline Enhanced density of the peri-intestinal fat & 12 & $0(0.0)$ & 35 & $5(14.3)$ & 0.309 \\
\hline Enlarged lymph nodes & 12 & $2(16.7)$ & 35 & $21(60.0)$ & 0.010 \\
\hline Fistula & 12 & $0(0.0)$ & 35 & $4(11.4)$ & 0.560 \\
\hline
\end{tabular}

CMUSE cryptogenic multifocal ulcerous stenosing enteritis; SBCD small bowel Crohn's disease; CTE computed tomography enterography 

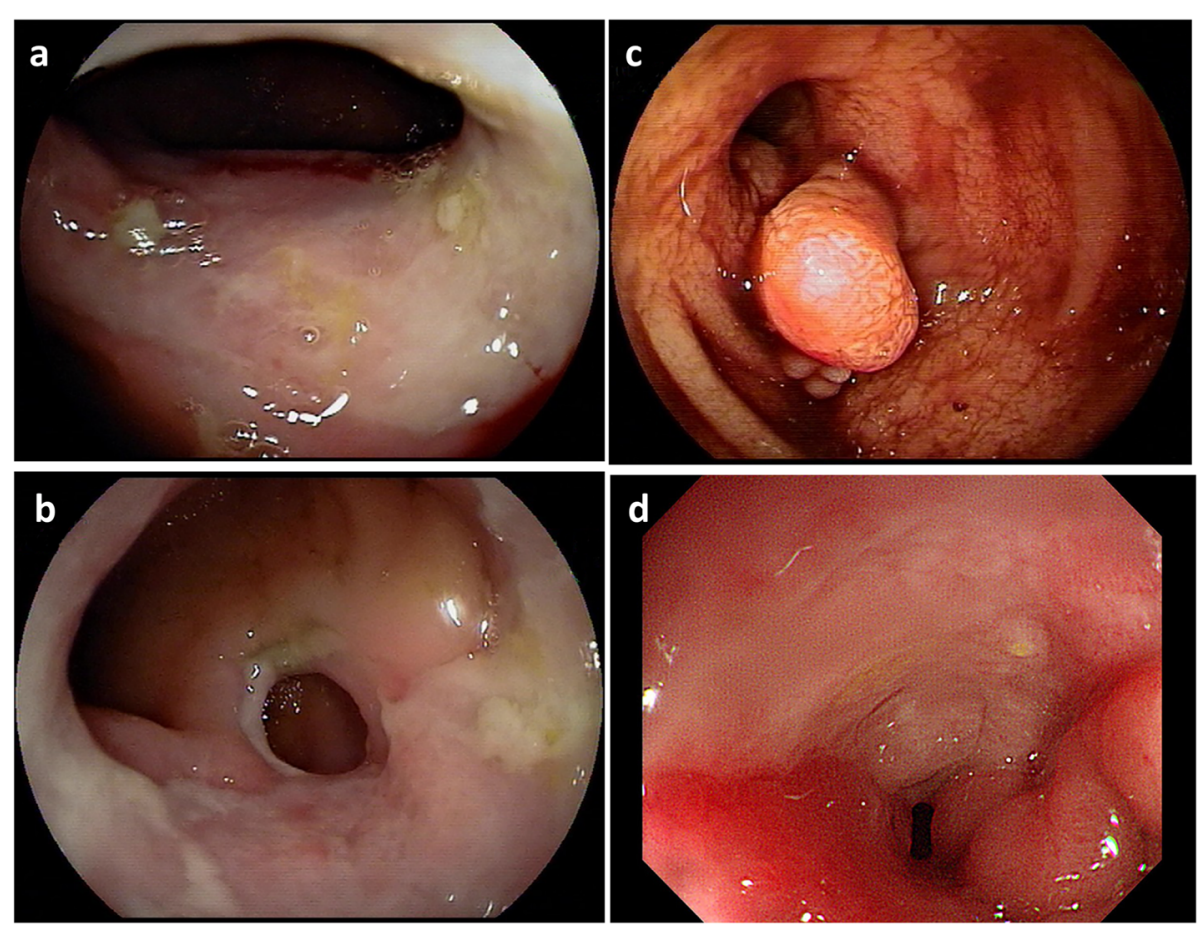

Fig. 2 The endoscopic features of CMUSE and SBCD patients. $\mathbf{a}$ and $\mathbf{b}$ were double-balloon enteroscopy images from a patient with CMUSE showing multiple centripetal annular stenosis with circumferential ulcers located on of the fourth group small intestine. c was a double-balloon enteroscopy image from a SBCD patients showing luminal narrowing with multiple inflammatory polyp on anal site of the sixth group small intestine. $\mathbf{d}$ was a coloscopy image from patients with SBCD revealing a longitudinal ulcer with cobblestone appearance on the opposite site of terminal ileum

Similarly, the incidence of transmural inflammation was higher in SBCD patients $(16,64.0 \%)$ than CMUSE patients $(1,10.0 \%)(P=0.007)$.

\section{Discussion}

Our study showed the following similarities between CMUSE and SBCD: (1) Both diseases had a chronic and recurrent course; (2) Abdominal pain was the most common reporting and persistent symptom in both entities; (3) Both diseases were associated with extra-intestinal manifestations such as oral ulcers; (4) Anemia and hypoalbuminemia frequently occurred in both diseases; (5) Positive ASCA was present in both CD and CMUSE [12]. (5) Lesions of CMUSE may be separated by normal mucosa, mimicking skip lesions of $\mathrm{CD}$. (6) Both diseases most commonly involved ileum [13]. Although rare, CMUSE can affect duodenum and ileocecal regions, consistent with previous reports [14]. (7) Intestinal bleeding and obstruction were characteristic for both SBCD and CMUSE. Given these similarities, it is often difficult to distinguish CMUSE from SBCD based on clinical, radiographic, and endoscopic features [5]. In fact, half of CMUSE patients in our cohort had been misdiagnosed with $\mathrm{CD}$ before the correct diagnosis was made.
Beyond these similarities, however, our study did reveal some useful clues to distinguish these two diseases. First, hematochezia $(71.4 \%$ vs $37.7 \%)$ was nearly two times more often in CMUSE than in SBCD, while diarrhea was present in about one third patients with $\mathrm{SBCD}$ but was absent in CMUSE. Intestinal strictures were universally present in all CMUSE patients but only occurred in about two third of patients with SBCD. Intraabdominal fistula, resulting from deep transmural ulcer, was considered to be diagnostic of CD [15]. But in this study the incidence of fistula in CMUSE and SBCD patients had no significant differences $(0.0 \%$ vs $11.5 \%)$.. According to current literature [11], only $15.5 \%$ of $C D$ patients have penetrating lesions (fistulas, phlegmons or abscesses) at the time of diagnosis. Limited sample size and low incidence of fistula may explain the lacking of statistical significance in this study.

Our study confirmed that serum inflammatory markers such as ESR and hsCRP elevated more often in SBCD than in CMUSE patients. For example, ESR was normal in all cases of CMUSE, consistent with another study that enrolled 17 CMUSE patients in France [10]. In contrast, ESR was elevated in half of SBCD patients and hsCRP in about two thirds. High hsCRP in 28.6\% CMUSE patients in our study may results from inflammatory response following 
Table 3 Endoscopic features of CMUSE and SBCD patients

\begin{tabular}{|c|c|c|c|c|c|}
\hline \multirow[t]{2}{*}{ Characteristics } & \multicolumn{2}{|c|}{ CMUSE } & \multicolumn{2}{|c|}{ SBCD } & \multirow[t]{2}{*}{$P$ value } \\
\hline & $\mathrm{N}$ & $n(\%)$ & $\mathrm{N}$ & $n(\%)$ & \\
\hline Number of patients taking endoscopy & 14 & $13(92.9)$ & 61 & $54(88.5)$ & / \\
\hline Coloscopy & 14 & $11(78.6)$ & 61 & $43(70.5)$ & 0.782 \\
\hline Double-balloon enteroscopy & 14 & $12(85.7)$ & 61 & $22(36.1)$ & 0.001 \\
\hline Capsule endoscopy & 14 & $5(35.7)$ & 61 & $15(24.6)$ & 0.607 \\
\hline Capsule retention & 5 & $3(60.0)$ & 15 & $3(20.0)$ & 0.131 \\
\hline Gastroscopy & 14 & $12(85.7)$ & 61 & $36(59.0)$ & 0.061 \\
\hline \multicolumn{6}{|l|}{ Lesion detected by endoscope } \\
\hline Ulcer & 13 & $11(84.6)$ & 54 & $43(79.6)$ & 0.986 \\
\hline \multicolumn{6}{|l|}{ Number of ulcers } \\
\hline 1 & 11 & $1(9.1)$ & 43 & $11(25.6)$ & 0.498 \\
\hline$\geq 2$ & 11 & $8(72.7)$ & 43 & $27(62.8)$ & \\
\hline Unknown & 11 & $2(18.2)$ & 43 & $5(11.7)$ & / \\
\hline \multicolumn{6}{|l|}{ Ulcer type } \\
\hline Longitudinal ulcer & 11 & $0(0.0)$ & 43 & $16(37.2)$ & 0.041 \\
\hline Dot ulcer & 11 & $2(18.2)$ & 43 & $7(16.3)$ & 1.000 \\
\hline Circumferential ulcer & 11 & $6(54.6)$ & 43 & $8(18.6)$ & 0.041 \\
\hline Oval ulcer & 11 & $2(18.2)$ & 43 & $7(16.3)$ & 1.000 \\
\hline Irregular ulcer & 11 & $1(9.1)$ & 43 & $19(44.2)$ & 0.072 \\
\hline Unknown & 11 & $1(9.1)$ & 43 & $1(2.4)$ & / \\
\hline Stricture & 13 & $9(69.2)$ & 54 & $16(29.6)$ & 0.020 \\
\hline \multicolumn{6}{|l|}{ Number of strictures } \\
\hline 1 & 9 & $2(22.2)$ & 16 & $11(68.8)$ & 0.013 \\
\hline$\geq 2$ & 9 & $4(44.5)$ & 16 & $3(18.7)$ & / \\
\hline Unknown & 9 & $3(33.3)$ & 16 & $2(12.5)$ & \\
\hline Fistula & 13 & $1(7.7)$ & 54 & $0(0.0)$ & 0.194 \\
\hline Hyperplastic lesions & 13 & $3(23.1)$ & 54 & $15(27.8)$ & 1.000 \\
\hline Pseudo-polyps & 3 & $1(33.3)$ & 15 & $5(33.3)$ & 1.000 \\
\hline Nodular lesions & 3 & $1(33.3)$ & 15 & $8(53.3)$ & 1.000 \\
\hline Eminence lesions & 3 & $2(66.7)$ & 15 & $3(20.0)$ & 0.172 \\
\hline Cobblestone appearance & 13 & $0(0.0)$ & 54 & $4(7.4)$ & 1.000 \\
\hline
\end{tabular}

CMUSE cryptogenic multifocal ulcerous stenosing enteritis; $S B C D$ small bowel Crohn's disease

acute exacerbation of small bowel obstruction. CTE is widely used for the diagnosis, evaluation and surveillance of small bowel lesions. Our study confirmed that extra-enteric findings, such as enlarged intraabdominal lymph nodes, were significantly more common in SBCD patients. These findings should remind clinicians that extra-luminal manifestations on radiographic examination are useful in differentiating CMUSE from SBCD $[2,16]$. Endoscopy allows for direct visualization and biopsy for small bowel lesions. In our study a vast majority of both CMUSE and SBCD patients underwent at least once endoscopic examination. Double-balloon enteroscopy plays an essential role in the diagnosis of CMUSE and SBCD. Ulcer morphology and number of strictures detected by endoscopy helps to discriminate CMUSE and SBCD. Consistent with the literature $[16,17]$, longitudinal ulcer $(37.2 \%$ vs $0.0 \%)$ was diagnostic for SBCD patients, while CMUSE patients more often developed circumferential ulcer (54.6\% vs $18.6 \%)$ than SBCD.

According to histological examination, CMUSE and SBCD differs in ulcer locations, ulcer depth, and transmural inflammation. Ulcers are located on the sites of stricture in all CMUSE patients, but in SBCD patient ulcers often present at the oral side of strictures, probably due to elevated intraluminal pressure arising from distal obstruction [10]. In terms of depth, ulcers in CMUSE patients were all superficial, limited within mucosal and submucosal layers. Ulcers in SBCD, in contrast, tended 
Table 4 Pathologic features of CMUSE and SBCD patients

\begin{tabular}{|c|c|c|c|c|c|}
\hline \multirow[t]{2}{*}{ Characteristics } & \multicolumn{2}{|c|}{ CMUSE } & \multicolumn{2}{|c|}{ SBCD } & \multirow[t]{2}{*}{$P$ value } \\
\hline & $\mathrm{N}$ & $\mathrm{n}(\%)$ & $\mathrm{N}$ & $\mathrm{n}(\%)$ & \\
\hline Ulcer & 10 & $10(100.0)$ & 25 & $18(72.0)$ & 0.084 \\
\hline \multicolumn{6}{|l|}{ Number of ulcers } \\
\hline 1 & 10 & $1(10.0)$ & 18 & $3(11.1)$ & \multirow[t]{3}{*}{1.000} \\
\hline$\geq 2$ & 10 & $8(80.0)$ & 18 & $15(72.2)$ & \\
\hline Unknown & 10 & $1(10.0)$ & 18 & $0(0.0)$ & \\
\hline \multicolumn{6}{|l|}{ Depth of ulcer } \\
\hline Deep & 10 & $0(0.0)$ & 18 & $8(44.4)$ & \multirow[t]{3}{*}{0.003} \\
\hline Superficial & 10 & $10(100.0)$ & 18 & $5(27.8)$ & \\
\hline Unknown & 10 & $0(0.0)$ & 18 & $5(27.8)$ & \\
\hline Ulcer located at stricture site & 10 & $9(90.0)$ & 18 & $1(5.6)$ & 0.000 \\
\hline Strictures & 10 & $10(100.0)$ & 25 & $18(72.0)$ & 0.084 \\
\hline 1 & 10 & $2(20.0)$ & 18 & $7(38.9)$ & \multirow[t]{2}{*}{0.417} \\
\hline$\geq 2$ & 10 & $8(80.0)$ & 18 & $11(61.1)$ & \\
\hline Cobblestone appearance & 10 & $0(0.0)$ & 25 & $2(8.0)$ & 1.000 \\
\hline Transmural inflammation & 10 & $1(10.0)$ & 25 & $16(64.0)$ & 0.007 \\
\hline Non- caseous epithelioid granulomas & 10 & $0(0.0)$ & 25 & $1(4.0)$ & 1.000 \\
\hline
\end{tabular}

CMUSE cryptogenic multifocal ulcerous stenosing enteritis; $S B C D$ small bowel Crohn's disease

to be deep with the most characteristic finding of "fissure-like". Noteworthy is that the depth of ulcers in SBCD correlates with disease progression, making it possible that superficial ulcers are present in SBCD at early stage. In the SBCD group of this study, nearly half patients presented deep ulcers but about one fourth patients did have superficial ulcers only. Transmural inflammation, a pathognomonic histological finding in CD, occurred more common in SBCD (64.0\%) compared with CMUSE (10.0\%) patients in our study. Another typical sign of $\mathrm{CD}$, namely non-caseous epithelioid granuloma, was not significant different between the two groups probably due to its low occurrence rate and limited sample size obtained by enteroscopy. Other authors

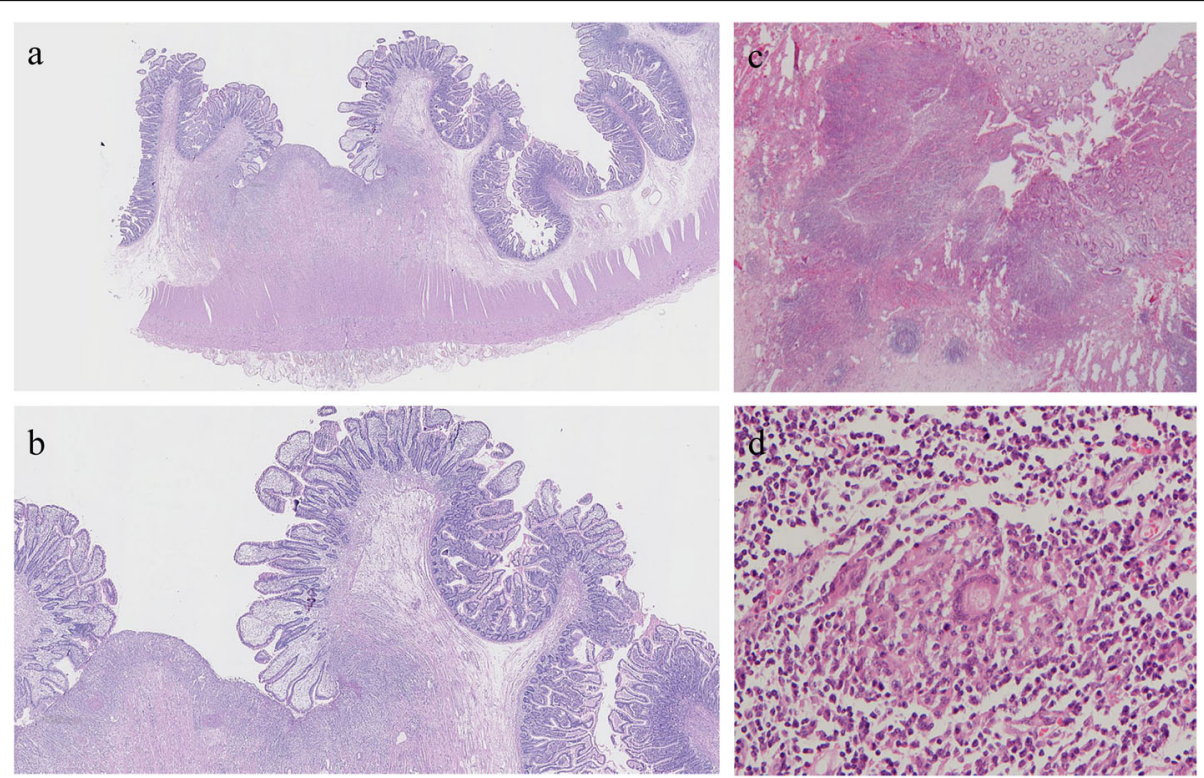

Fig. 3 The pathologic features of CMUSE and SBCD patients. Microscopic findings on a surgical specimen obtained from a CMUSE patient stained with hematoxylin and eosin (HE) showed superficial ulcer affecting the mucosa and submucosa $(\mathbf{a}: 4 \times, \mathbf{b}: 10 \times)$. In comparison, pathologic tissue stained with HE in patients with SBCD showed deep ulcer with transmural inflammation(c:10x)and non- caseous epithelioid granulomas (d:20X) 
reported non-caseous epithelioid granuloma in only 13 to $36 \%$ of patients with $\mathrm{CD}[18,19]$. Therefore, $\mathrm{CD}$ should not be excluded based on lacking of non-caseous epithelioid granuloma due to its low sensitivity.

Significant advances in the pathogenesis of CMUSE has been made recently since an attempt has been made to decode its genetic basis. CMUSE is believed to be an "autosomal recessive" disease resulted from mutation of gene leading to the impaired prostaglandin function such SLCO2A1 gene [20, 21] and/or PLA2G4A gene [14]. Gene mutation analysis, immunohistochemical staining for SLCO2A1 protein in gastroduodenal tissues and prostaglandin $\mathrm{E}$ major urinary metabolites (PGEMUM), a major urinary metabolite derived from PGE2, may help differential those two diseases [22-25]. However, such conclusions could not be made from our study because we failed to get these information. This is one of the limitations of our study. There were several other limitations in our study. Since this study was a retrospective study in a single center, and all patients enrolled were hospitalized, certain selection bias was inevitable. Besides, the number of CMUSE patients enrolled was limited due to the rarity of the disease. Further large multi-center studies are needed to explore the differential markers between these two entries.

\section{Conclusions}

In conclusion, CMUSE and SBCD have overlapping features and discrimination between the two conditions can be difficult. However, some valuable clues are helpful in the differential diagnosis, including gastrointestinal symptoms such as hematochezia, fever and diarrhea, the complications such as intestinal stenosis, terminal ileum involving, anemia, level of serum inflammatory markers, CTE features including extra-enteric findings and enlargement of the abdominal lymph nodes, endoscopic features such as ulcer types and stricture number and pathologic features such as ulcer depth, ulcer location and transmural inflammation.

\section{Supplementary information}

Supplementary information accompanies this paper at https://doi.org/10. 1186/s12876-020-01389-7.

\section{Additional file 1.}

\section{Abbreviations}

ANCA: Antineutrophil cytoplasmic antibodies; ASCA: Antisacchromyces cerevisia antibody; BMl: Body mass index; CD: Crohn's disease; CMUSE: Cryptogenic multifocal ulcerous stenosing enteritis; CTE: Computed tomography enterography; ESR: Erythrocyte sedimentation rate; hsCRP: High sensitivity $C$ reactive protein; NSAIDs: Nonsteroidal anti-inflammatory drugs: PGE-MUM: Prostaglandin E major urinary metabolites; SBCD: Small bowel Crohn's disease: SD: Standard deviation; WBC: White blood cells

\section{Authors' contributions}

DC: Patient recruitment, data collection and analysis and writing up of the first draft of the paper. WL: Study design, data interpretation and paper revision. WXZ: Study design, data interpretation and paper revision. WYZ: Patinet recruitment and data collection and analysis. DW: Study design, data analysis and interpretation and manuscript revision. JMQ: Study design, data analysis and interpretation, manuscript revision and funding support. All authors read and approved the final manuscript.

\section{Funding}

This work was supported by grants from Health Research and Special Projects (grant number. 201002020) funded by National health commission of the people's republic of China. The funders had no role in study design, data collection and analysis, decision to publish, or preparation of the manuscript.

\section{Availability of data and materials}

The datasets used during the current study are presented in the main manuscript.

Ethics approval and consent to participate

All patients signed agreement for this study. The study was approved by the Ethical Committee of Peking Union Medical College Hospital (ZS-1798).

Consent for publication

Not Applicable.

Competing interests

The authors declare that they have no competing interests.

\section{Author details}

'Department of Gastroenterology, Peking Union Medical College Hospital, Chinese Academy of Medical Sciences and Peking Union Medical College, Shuaifuyuan, No.1, Dongcheng District, Beijing 100730, China. ${ }^{2}$ Department of Radiology, Peking Union Medical College Hospital, Chinese Academy of Medical Sciences and Peking Union Medical College, Beijing, China.

${ }^{3}$ Department of Pathology, Peking Union Medical College Hospital, Chinese Academy of Medical Sciences and Peking Union Medical College, Beijing, China.

Received: 9 February 2020 Accepted: 16 July 2020

Published online: 05 August 2020

\section{References}

1. Perlemuter G, Chaussade S, Soubrane O, Degoy A, Louvel A, Barbet $P$, et al. Multifocal stenosing ulcerations of the small intestine revealing vasculitis associated with C2 deficiency. Gastroenterology. 1996;110:1628-32. https:// doi.org/10.3748/wjg.v23.i25.4615

2. Park MJ, Lim JS. Computed tomography enterography for evaluation of inflammatory bowel disease. Clin Endosc. 2013;46:327-36. https://doi.org/10. 5946/ce.2013.46.4.327

3. Hall B, Holleran G, McNamara D. Small bowel Crohn's disease: an emerging disease phenotype? Dig Dis. 2015;33:42-51. https://doi.org/10.1159/ 000366047

4. Debray C, Besancon F, Hardouin JP, Martin E, Marche C, Khoury K. Cryptogenetic plurifocal ulcerative stenosing enteritis. Arch Mal Appar Dig Mal Nutr. 1964;53:193-206

5. Chung SH, Park SU, Cheon JH, Kim ER, Byeon JS, Ye BD, et al. Clinical characteristics and treatment outcomes of cryptogenic multifocal ulcerous stenosing enteritis in Korea. Dig Dis Sci. 2015;60:2740-5. https://doi.org/10. 1007/s10620-015-3595-y.

6. Kohoutová D, Bártová J, Tachecí I, Rejchrt S, Repák R, Kopáčová M, et al. Cryptogenic multifocal ulcerous stenosing enteritis: a review of the literature. Gastroenterol Res Pract. 2013;2013:1-7. https://doi.org/10.1155/ 2013/918031.

7. Kim CW, Yu CS, Yoon YS, Yoon SN, Lim SB, Kim JC. Steroid-refractory cryptogenic multifocal ulcerous stenosing enteritis. Am J Surg. 2011;202: e48-51. https://doi.org/10.1016/j.amjsurg.2010.09.020.

8. Heiko DS, Elisabeth M, Veerle VM, Maarten S, Paul P. Tom M. Infliximab induces remission in cryptogenic multifocal ulcerous stenosing enteritis: first 
case. World J Gastroenterol. 2013;19:1661-4. https://doi.org/10.3748/wjg.v19. i10.1661.

9. Kwon SO, Kim YS, Kim SY, Hong SW, Lee HK, Moo JS. A case of cryptogenic multifocal ulcerous stenosing enteritis: differential diagnosis from Crohn's disease. J Gastrointestin Liver Dis. 2012;21:309-12.

10. Perlemuter G, Guillevin L, Legman P, Weiss L, Couturier D, Chaussade S. Cryptogenetic multifocal ulcerous stenosing enteritis: an atypical type of vasculitis or a disease mimicking vasculitis. GUT. 2001;48:333-8. https://doi. org/10.1136/gut.48.3.333.

11. Gomollón F, Dignass A, Annese V, Tilg H, Assche GV, Lindsay JO, et al. 3Rd European Evidence-based Consensus on the Diagnosis and Management of Crohn's Disease 2016: Part 1: diagnosis and medical management. J Crohns Colitis. 2016(11):3-25. https://doi.org/10.1093/ecco-jcc/jjw168.

12. Wang ZZ, Shi K, Peng J. Serologic testing of a panel of five antibodies in inflammatory bowel diseases: diagnostic value and correlation with disease phenotype. Biomed Rep. 2017;6:401-10. https://doi.org/10.3892/br.2017.860.

13. Matsumoto T, lida M, Matsui T, Yao T. Chronic nonspecific multiple ulcers of the small intestine: a proposal of the entity from Japanese gastroenterologists to Western enteroscopists. Gastrointest Endosc. 2007;66: S99-S107. https://doi.org/10.1016/j.gie.2007.01.004.

14. Brooke MA, Longhurst HJ, Plagnol V, Kirkby NS, Mitchell JA, Rüschendorf F, et al. Cryptogenic multifocal ulcerating stenosing enteritis associated with homozygous deletion mutations in cytosolic phospholipase A2-a. GUT. 2014;63:96-104. https://doi.org/10.1136/gutjnl-2012-303581.

15. Freeman HJ. Multifocal stenosing ulceration of the small intestine. World J Gastroenterol. 2009;15:4883-5. https://doi.org/10.3748/wjg.15.4883.

16. Paquet N, Glickman JN, Erturk SM, Ros PR, Heverhagen JT, Patak MA. Crohn's disease activity: abdominal computed tomography histopathology correlation. Eur J Radiol Open. 2016;3:74-8. https://doi.org/10.1016/j.ejro. 2016.03.001.

17. Chang DK, Kim JJ, Choi H, Eun CS, Han DS, Byeon JS, et al. Double balloon endoscopy in small intestinal Crohn's disease and other inflammatory diseases such as cryptogenic multifocal ulcerous stenosing enteritis (CMUSE). Gastrointest Endosc. 2007;66:96-8. https://doi.org/10.1016/j.gie. 2007.01.016

18. Lee $\mathrm{JM}$, Lee $\mathrm{K}$. Endoscopic diagnosis and differentiation of inflammatory bowel disease. Clin Endosc. 2016;49:370-5. https://doi.org/10.5946/ce.2016. 090 .

19. Mazor Y, Karban A, Nesher S, Weiss B, Esther LS, Levine A, et al. Granulomas in Crohn's disease: are newly discovered genetic variants involved? J Crohns Colitis. 2010;4:438-43. https://doi.org/10.1016/j.crohns.2010.02.006.

20. Umeno J, Hisamatsu T, Esaki M, Hirano A, Kubokura N, Asano K, et al. A hereditary enteropathy caused by mutations in the SLCO2A1 gene, encoding a prostaglandin transporter. PLoS Genet. 2015;11:e1005581. https://doi.org/10.1371/journal.pgen.1005581.

21. Umeno J, Esaki M, Hirano A, Fuyuno Y, Ohmiya N, Yasukawa S, et al. Clinical features of chronic enteropathy associated with SLCO2A1 gene: a new entity clinically distinct from Crohn's disease. J Gastroenterol. 2018;53:90715. https://doi.org/10.1007/s00535-017-1426-y.

22. Umeno J, Matsumoto T, Hirano A, Fuyuno Y, Esaki M. Genetic analysis is helpful for the diagnosis of small bowel ulceration. World J Gastroenterol. 2018;24:3198-200. https://doi.org/10.3748/wjg.v24.i28.3198.

23. Yamaguchi S, Yanai S, Nakamura S, Kawasaki K, Eizuka M, Uesugi N, et al. Immunohistochemical differentiation between chronic enteropathy associated with SLCO2A1 gene and other inflammatory bowel diseases. Intest Res. 2018;16:393-9. https://doi.org/10.5217/ir.2018.16.3.393.

24. Yanai S, Yamaguchi S, Nakamura S, Kawasaki K, Toya Y, Yamada N, et al. Distinction between chronic enteropathy associated with the SLCO2A1 gene and crohn's disease. Gut Liver. 2019;13:62-6. https://doi.org/10.5009/ gnl18261.

25. Matsuno $Y$, Umeno J, Esaki M, Hirakawa Y, Fuyuno Y, Okamoto $Y$, et al. Measurement of prostaglandin metabolites is useful in diagnosis of small bowel ulcerations. World J Gastroenterol. 2019;25:1753-63. https://doi.org/ 10.3748/wjg.v25.i14.1753.

\section{Publisher's Note}

Springer Nature remains neutral with regard to jurisdictional claims in published maps and institutional affiliations.

Ready to submit your research? Choose BMC and benefit from:

- fast, convenient online submission

- thorough peer review by experienced researchers in your field

- rapid publication on acceptance

- support for research data, including large and complex data types

- gold Open Access which fosters wider collaboration and increased citations

- maximum visibility for your research: over $100 \mathrm{M}$ website views per year

At BMC, research is always in progress.

Learn more biomedcentral.com/submissions 